\title{
Correction to: Mechanical Thrombectomy in Basilar Artery Occlusion
}

\section{Presence of Bilateral Posterior Communicating Arteries is a Predictor of Favorable Clinical Outcome}

\author{
Volker Maus ${ }^{1}$ Alev Kalkan ${ }^{1}$ Christoph Kabbasch ${ }^{1}$. Nuran Abdullayev ${ }^{1} \cdot$ Henning Stetefeld ${ }^{2}$. \\ Utako Birgit Barnikol ${ }^{3}$. Thomas Liebig ${ }^{4}$ Christian Dohmen ${ }^{2}$. Gereon Rudolf Fink ${ }^{2,5}$ • Jan Borggrefe' . \\ Anastasios Mpotsaris ${ }^{6}$
}

Published online: 9 January 2018

๑) Springer-Verlag GmbH Germany, part of Springer Nature 2018

\section{Correction to:}

\section{Clin Neuroradiol 2017}

https://doi.org/10.1007/s00062-017-0651-3

The original version of this article unfortunately contained a mistake. The presentation of Fig. 2 was incorrect. The corrected figure is given below.

The online version of the original article can be found under https://doi.org/10.1007/s00062-017-0651-3.

Volker Maus

volker.maus@uk-koeln.de

1 Department of Neuroradiology, University Hospital Cologne, Kerpener Str. 62, 50937 Cologne, Germany

2 Department of Neurology, University Hospital Cologne, Cologne, Germany

3 Clearing Unit Ethics, Medical Faculty of Cologne \& Research Unit Ethics, Department of Child and Adolescence Psychiatry, University Hospital Cologne, Cologne, Germany

4 Department of Neuroradiology, Charité, Berlin, Germany

5 Cognitive Neuroscience, Institute of Neuroscience and Medicine (INM-3), Research Centre Jülich, Jülich, Germany

6 Department of Neuroradiology, University Hospital Aachen, Aachen, Germany 


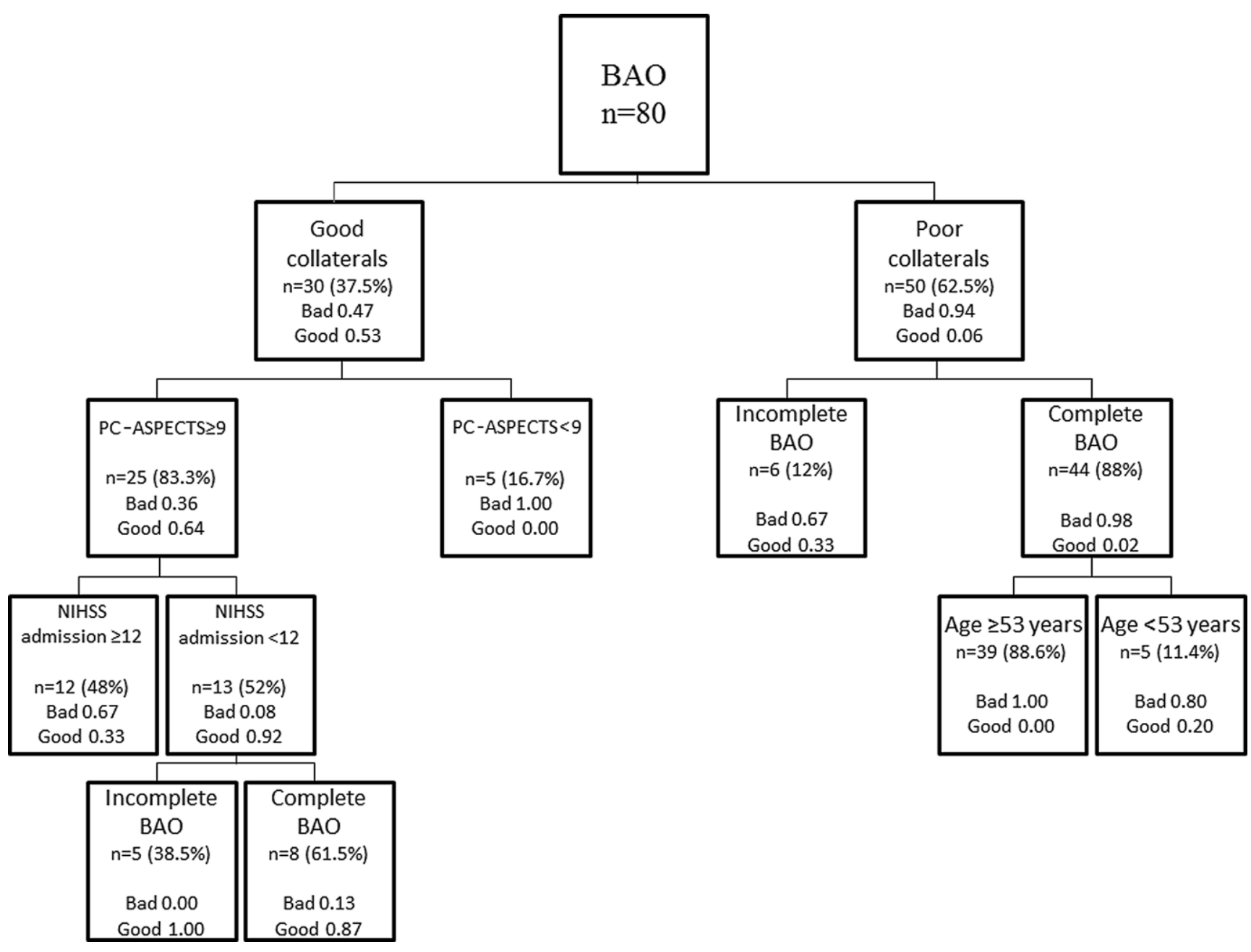

Fig. 2 Partition regression model showing priority of significant predictors of clinical outcome. BAO basilar artery occlusion, $P C$-ASPECTS posterior circulation Alberta Stroke Program early computed tomography score, NIHSS National Institute of Health Stroke Scale 